\title{
Design and Execution of the Hypersonic Inflatable Aerodynamic Decelerator Large-Article Wind Tunnel Experiment
}

Alan M. Cassell

NASA Ames Research Center, Entry Systems and Vehicle Development Branch $10^{\text {th }}$ International Planetary Probe Workshop, 17-21 June 2012, San Jose, CA, USA 


\section{Outline}

- HIAD Overview

- Test Design

- Assembly \& Integration

- Testing Operations

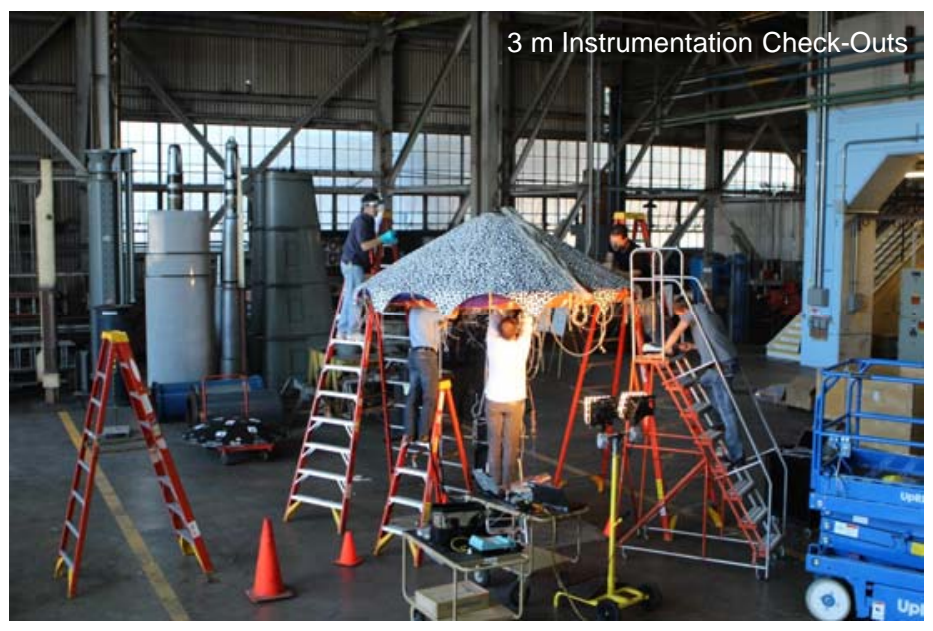

- Instrumentation \& Data Prodı

- Summary

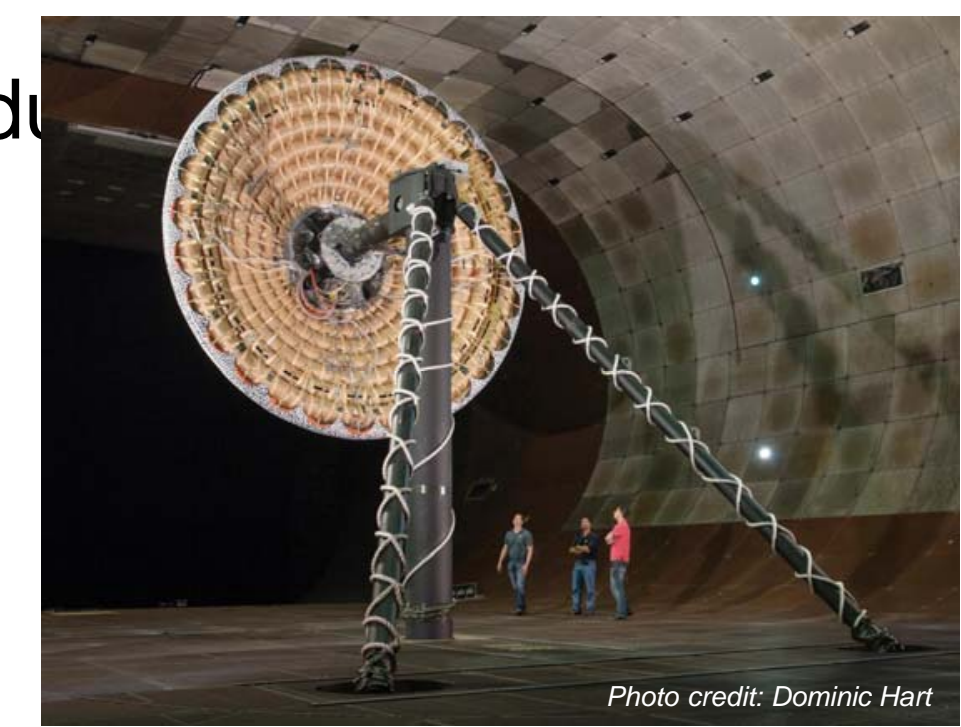




\section{HIAD Overview}

\section{Inflatable Aeroshell Structures Development}

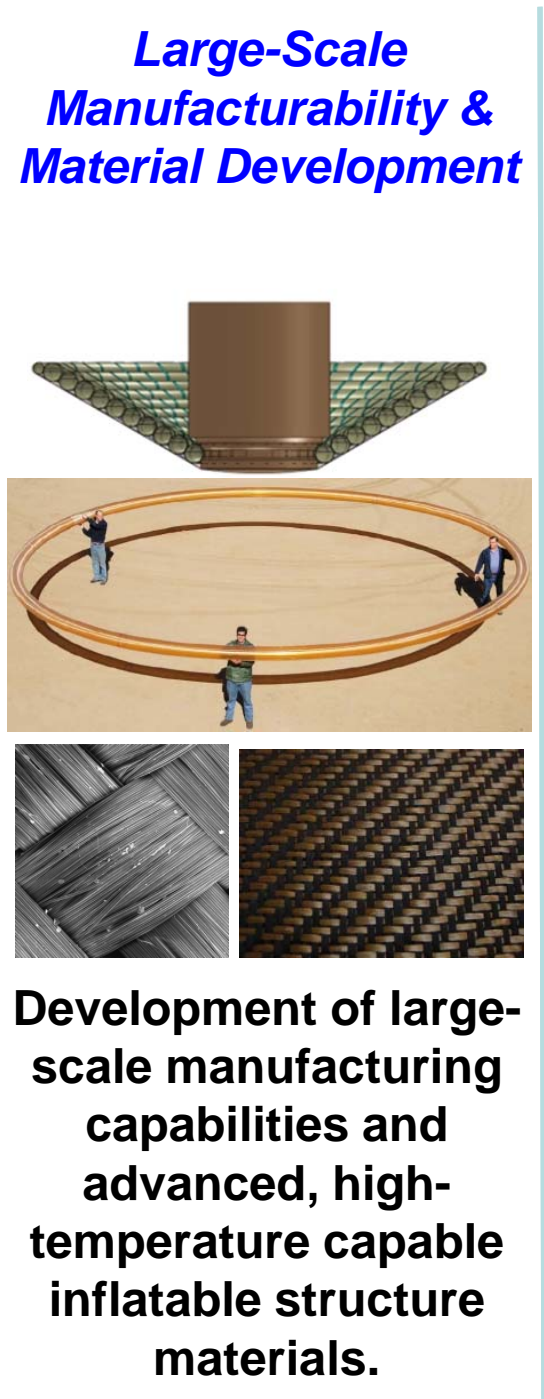

Large-Scale Static Load Testing \& Model Development
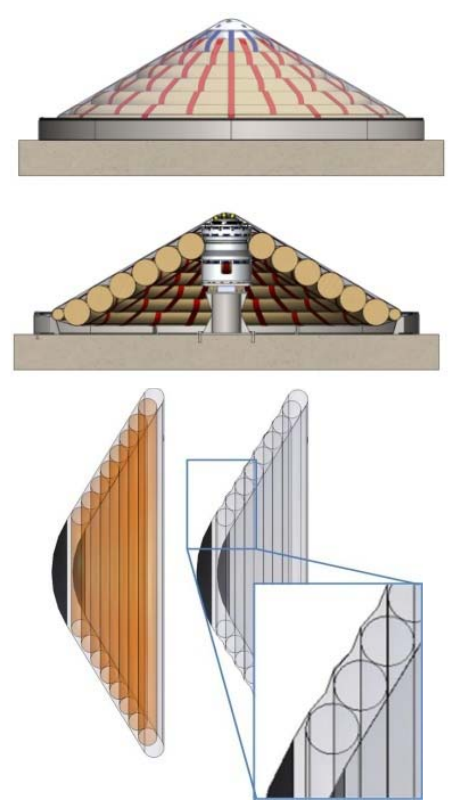

Ground test to demonstrate HIAD scalability and initial structural model development.
Large-Scale Wind Tunnel Testing \& Instrumentation Development

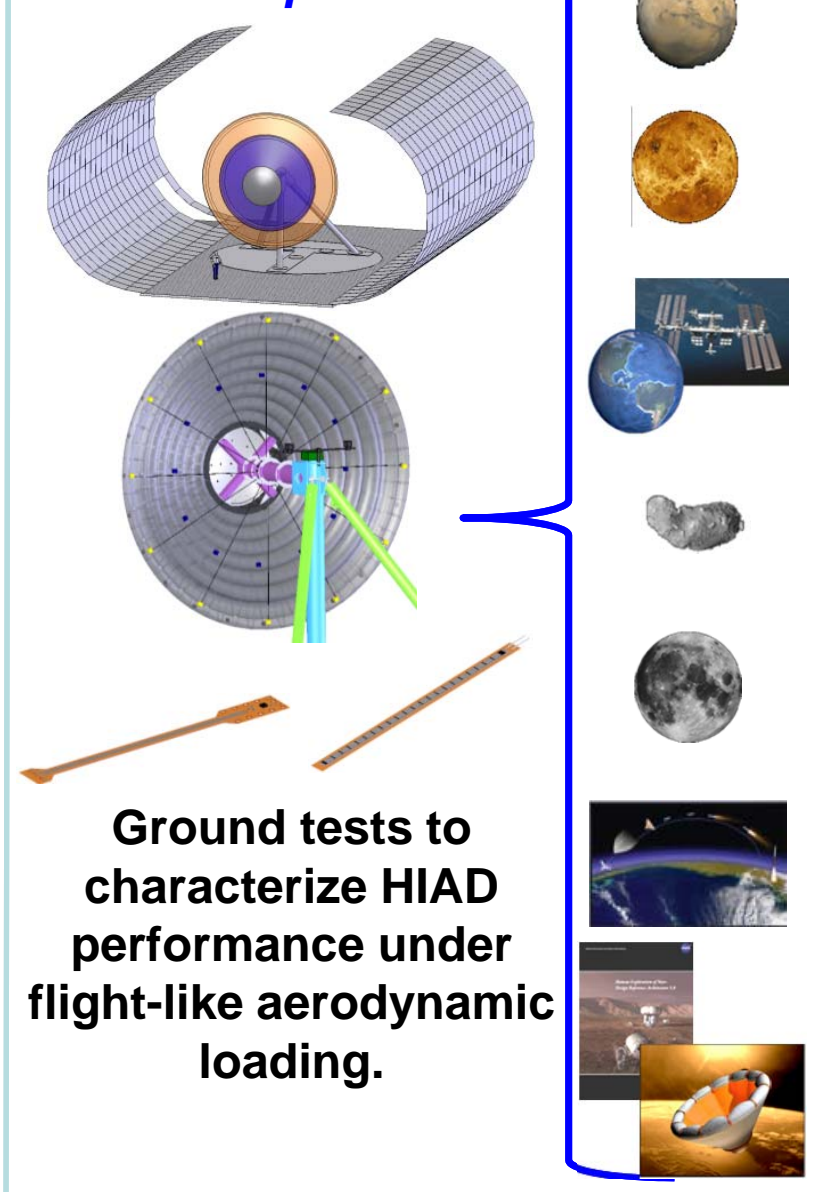

Mars robotic (SMD \& ESMD)

Venus missions (SMD)

LEO/ISS missions (SMD \& SOMD)

NEO return-robotic (SMD \& ESMD)

Lunar return-robotic (SMD \& ESMD)

Terrestrial robotic missions (DoD)

Technology development \& risk reduction for Human Mars missions ( $E$ ESMD) 


\section{HIAD Overview}

\section{The HIAD Mission Concept- HEART}

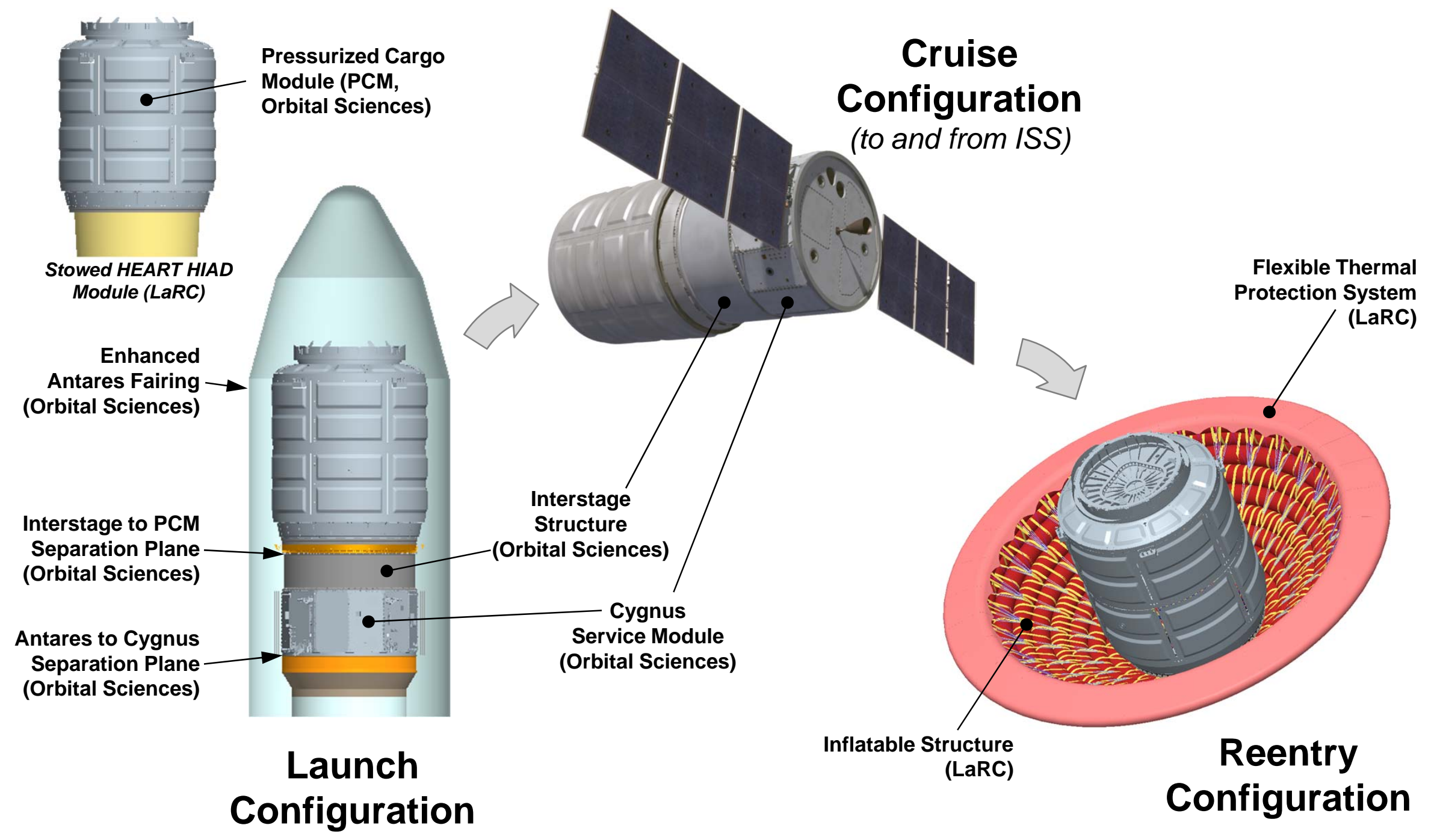




\section{HIAD Overview}

\section{HEART Trajectory}
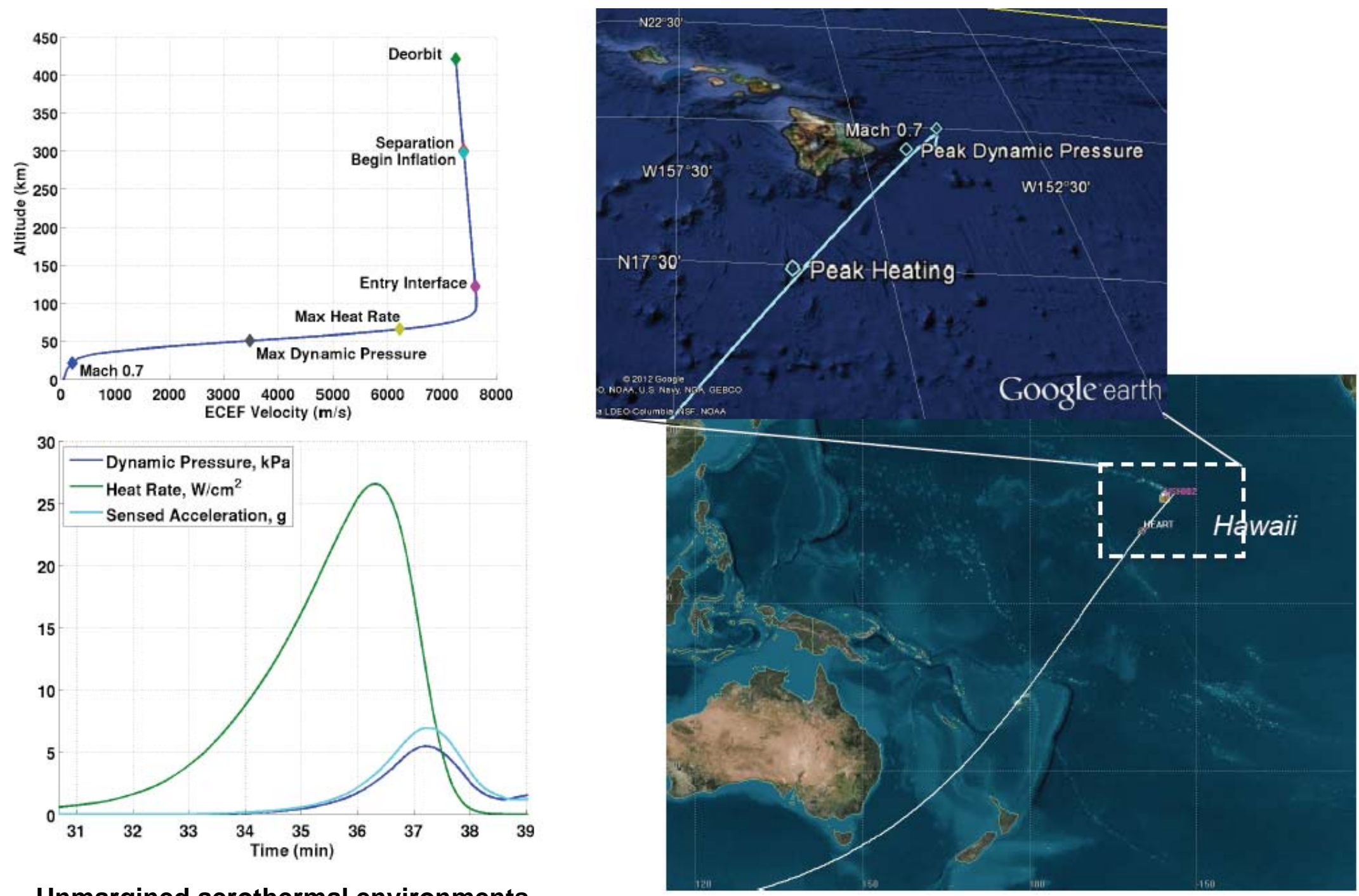

Unmargined aerothermal environments 


\section{Test Design}

\section{National Full-Scale Aerodynamics Complex}

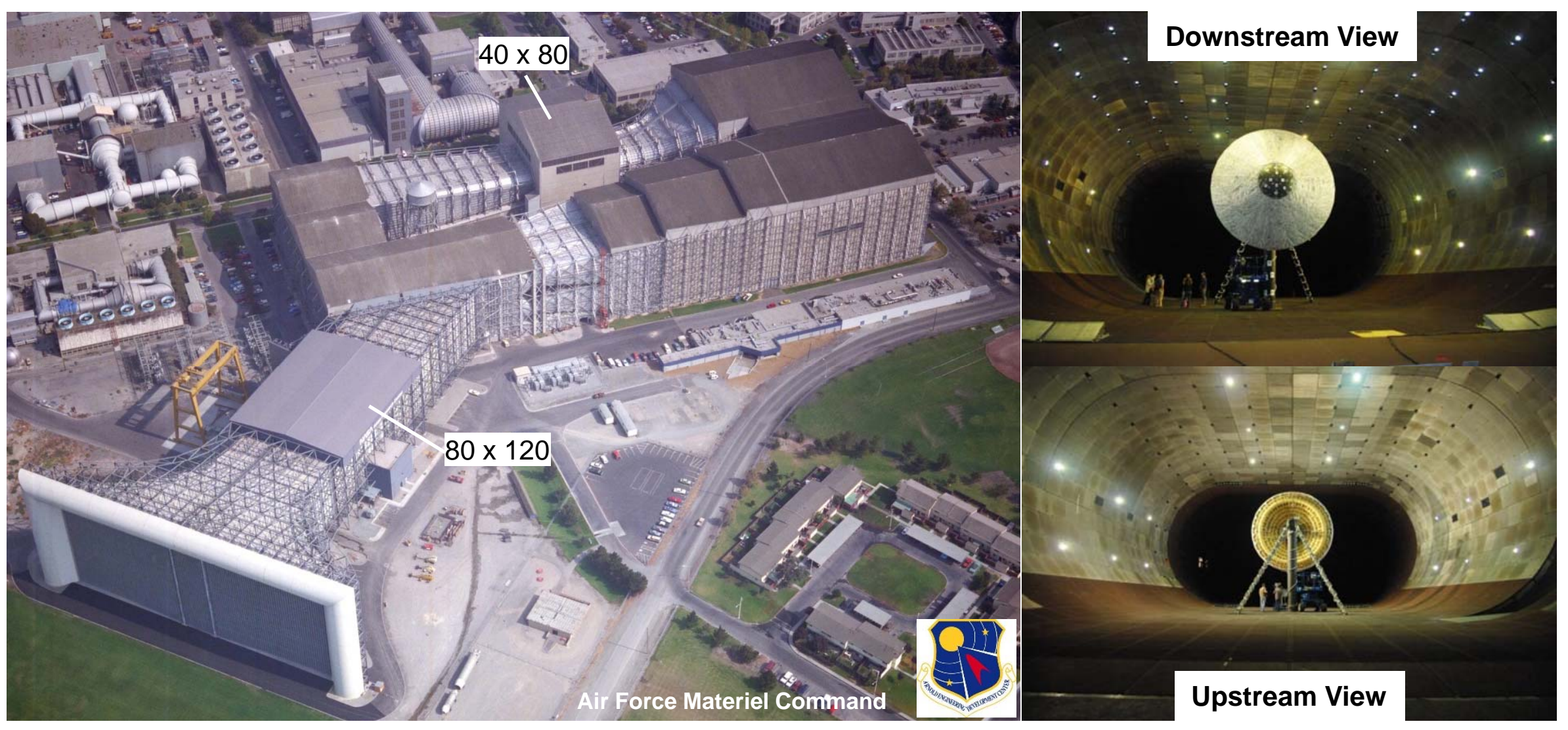

$40 \mathrm{ft} \times 80 \mathrm{ft}(12 \mathrm{~m} \times 24 \mathrm{~m})$ Test Section Operating Specifications

Semi-Elliptical Profile

Maximum Velocity- 300 knots $(154 \mathrm{~m} / \mathrm{s})$

Max Dynamic Pressure- 262 psf (12.5 kPa)

*Max Drag Load- 32,000 lbs 


\section{Test Design}

\section{Test Article Descriptions}

$\underline{6 \mathrm{~m} \text { Baseline }}$

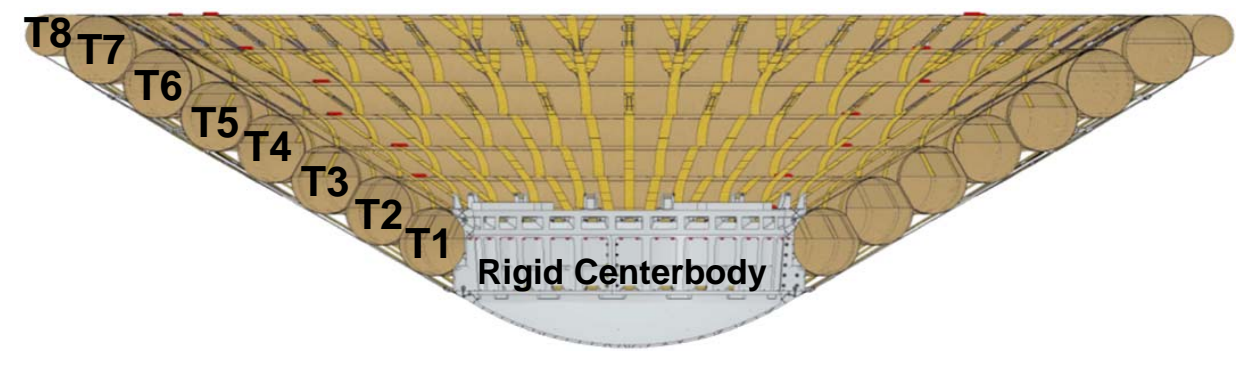

$6 \mathrm{~m}$ Tri-Torus

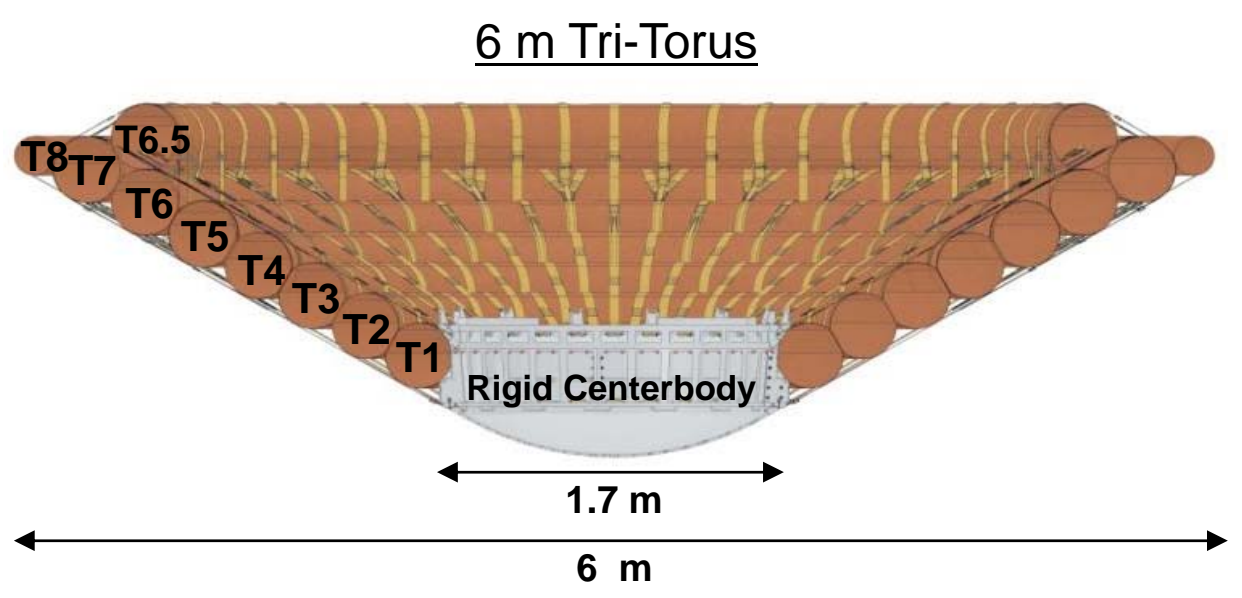

$\underline{3 m}$

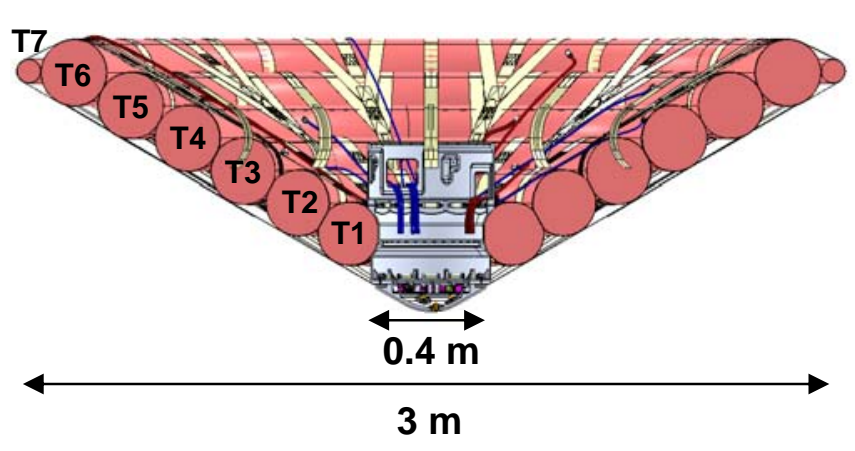




\section{Test Design}

\section{Test Matrix}
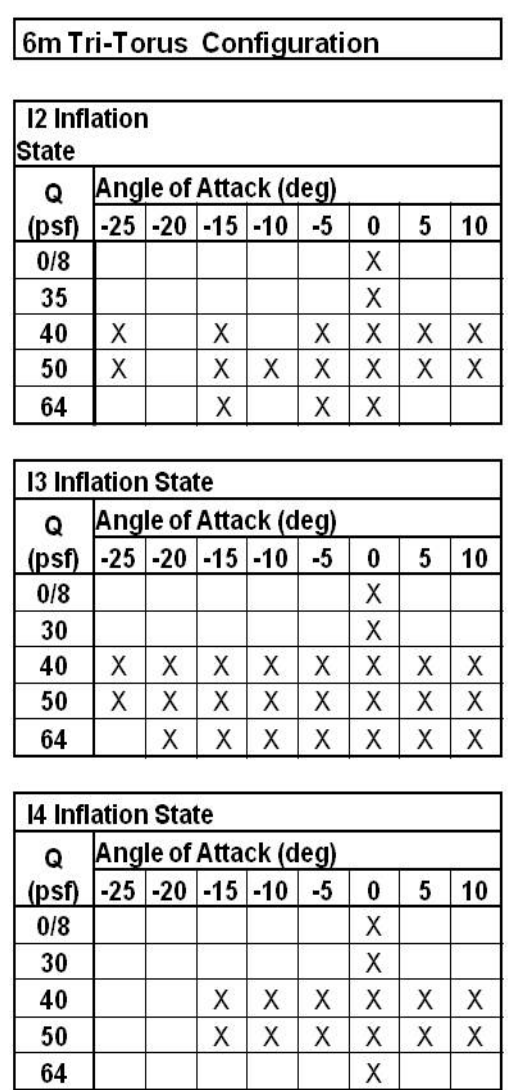
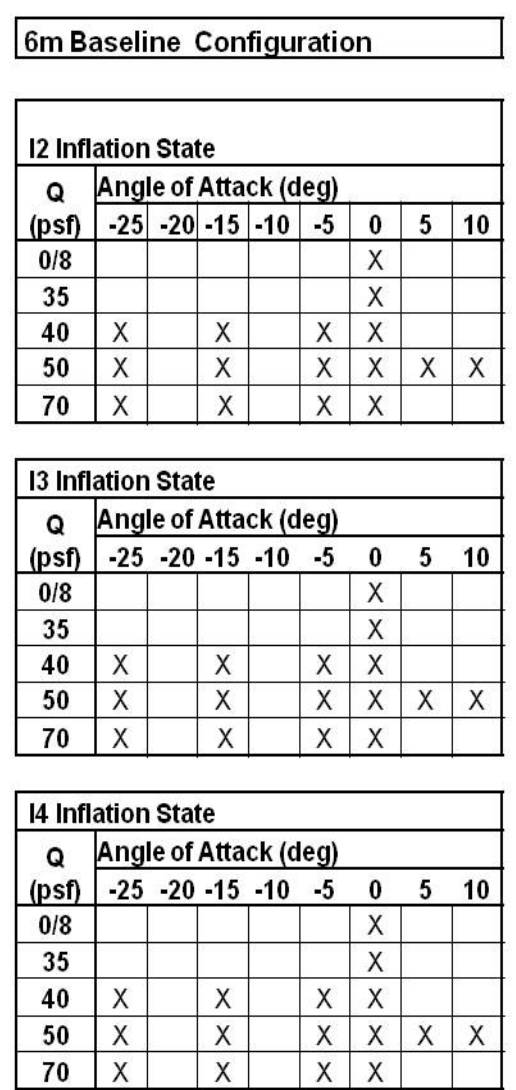

\begin{tabular}{|c|c|c|c|c|c|}
\hline \multicolumn{6}{|c|}{$3 \mathrm{~m}$ without TPS } \\
\hline \multicolumn{6}{|c|}{ I1 Inflation State } \\
\hline \multirow{2}{*}{$\begin{array}{c}Q Q \\
\text { (psf) }\end{array}$} & \multicolumn{5}{|c|}{ Angle of Attack (deg) } \\
\hline & -10 & -5 & 0 & 5 & 10 \\
\hline 8 & $x$ & $x$ & $\bar{X}$ & $\bar{X}$ & $X$ \\
\hline 40 & $\mathrm{X}$ & $\mathrm{X}$ & $\mathrm{x}$ & & \\
\hline 80 & $\mathrm{X}$ & $\mathrm{X}$ & $\mathrm{x}$ & $x$ & $\mathrm{X}$ \\
\hline 120 & $\mathrm{X}$ & $\mathrm{X}$ & $\mathrm{x}$ & $x$ & \\
\hline 160 & & & & & \\
\hline
\end{tabular}

$3 \mathrm{~m}$ with TPS

\begin{tabular}{|c|c|c|c|c|c|}
\hline \multicolumn{6}{|c|}{ I1 Inflation State } \\
\hline \multirow{2}{*}{$\begin{array}{c}Q \\
\text { (psf) }\end{array}$} & \multicolumn{5}{|c|}{ Angle of Attack (deg) } \\
\hline & -10 & -5 & 0 & 5 & 10 \\
\hline 8 & $\mathrm{X}$ & $\mathrm{X}$ & $\mathrm{X}$ & $\mathrm{X}$ & $\mathrm{X}$ \\
\hline 40 & $X$ & $\mathrm{X}$ & $x$ & & \\
\hline 80 & $X$ & $\mathrm{X}$ & $x$ & $\mathrm{X}$ & $\mathrm{X}$ \\
\hline 120 & $X$ & $\mathrm{X}$ & $\mathrm{X}$ & $X$ & $\mathrm{X}$ \\
\hline 160 & & $\mathrm{X}$ & $x$ & & \\
\hline
\end{tabular}

\begin{tabular}{|c|c|c|c|c|c|}
\hline \multicolumn{6}{|c|}{ I2 Inflation State } \\
\hline \multirow{2}{*}{$\begin{array}{c}Q \\
\text { (psf) }\end{array}$} & \multicolumn{5}{|c|}{ Angle of Attack (deg) } \\
\hline & -10 & -5 & 0 & 5 & 10 \\
\hline 8 & $\bar{X}$ & $X$ & $\mathrm{X}$ & $x$ & $\mathrm{X}$ \\
\hline 40 & $X$ & $x$ & $x$ & & \\
\hline 80 & $X$ & $X$ & $X$ & $X$ & $X$ \\
\hline 120 & & $X$ & $x$ & $x$ & $x$ \\
\hline
\end{tabular}

\section{Testing Approach}

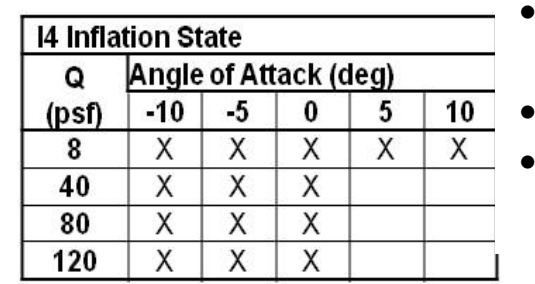

- Test from highest to lowest inflation setting

- Stabilize tunnel condition $\boldsymbol{q}$, then do AoA sweeps

- 60 sec dwell time at each point for data acquisition

Slew rate for turntable $(0.5 \mathrm{deg} / \mathrm{sec})$

- 379 total test points (with repeats) obtained 


\section{Assembly \& Integration}

Test Article Preparations

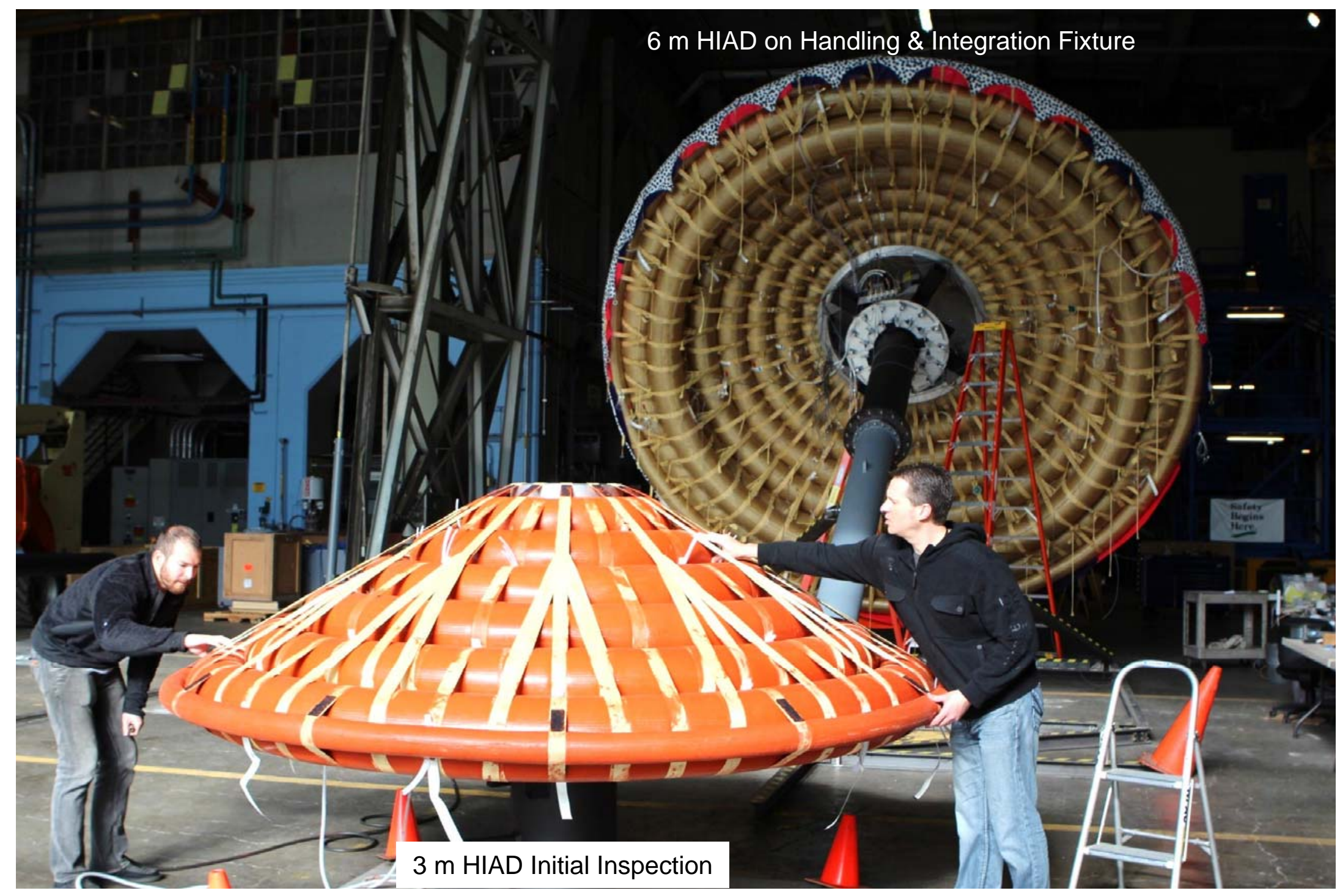




\section{Assembly \& Integration}

\section{Custom Handling \& Integration Fixture}

Key Features:

- Tilt via Facility Cranes to Transfer/Integration

Positions

- Manually Rotatable via Bearing

- Radial Rotation Lock

Allows:

- Facile Access- Fore \& Aft

- Rapid Instrumentation \& Pneumatic Line Integration

- Transfer to/from Test Section
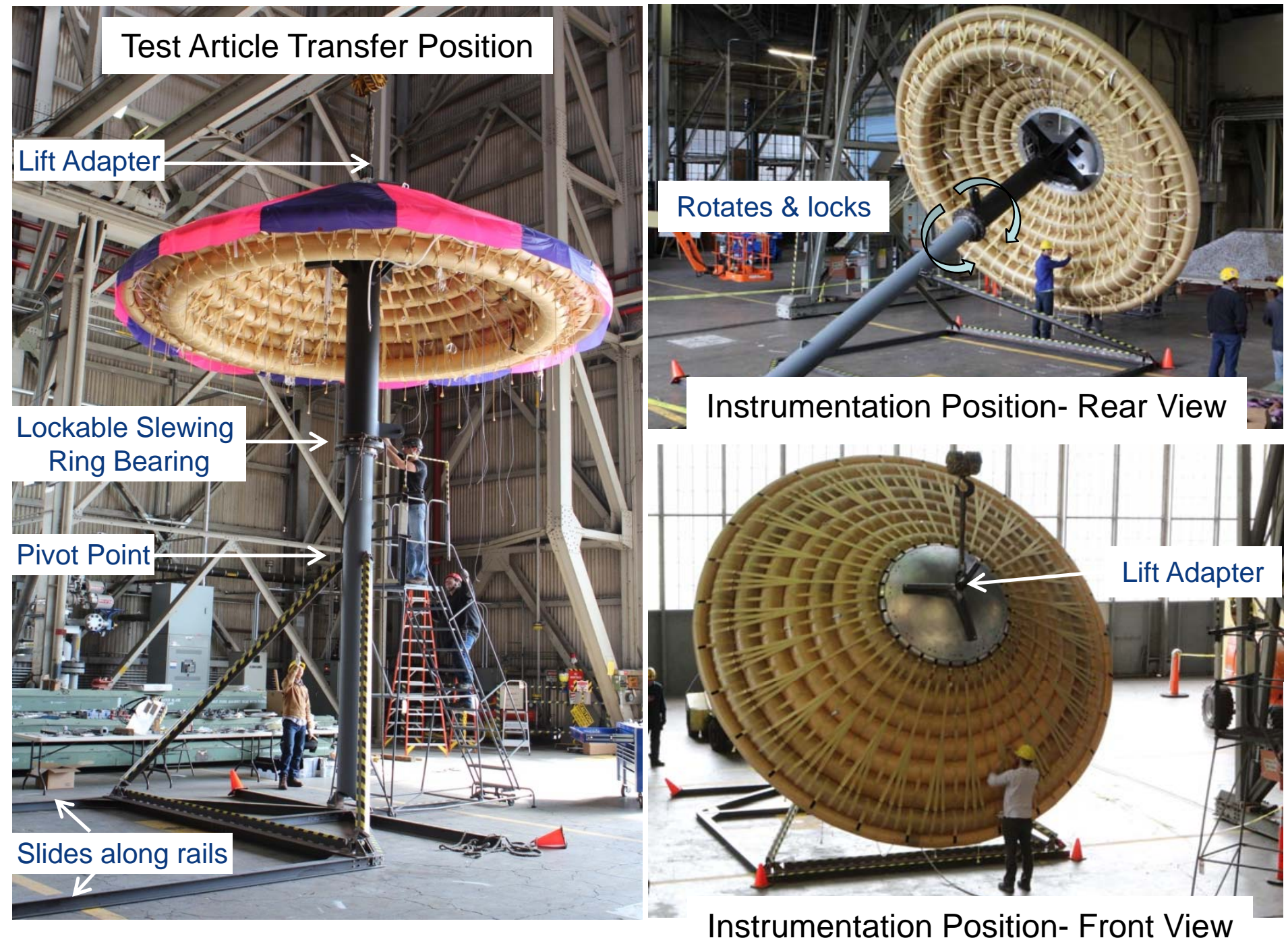


\section{Assembly \& Integration}

\section{Instrumentation \& Pressure Line Set-Up}

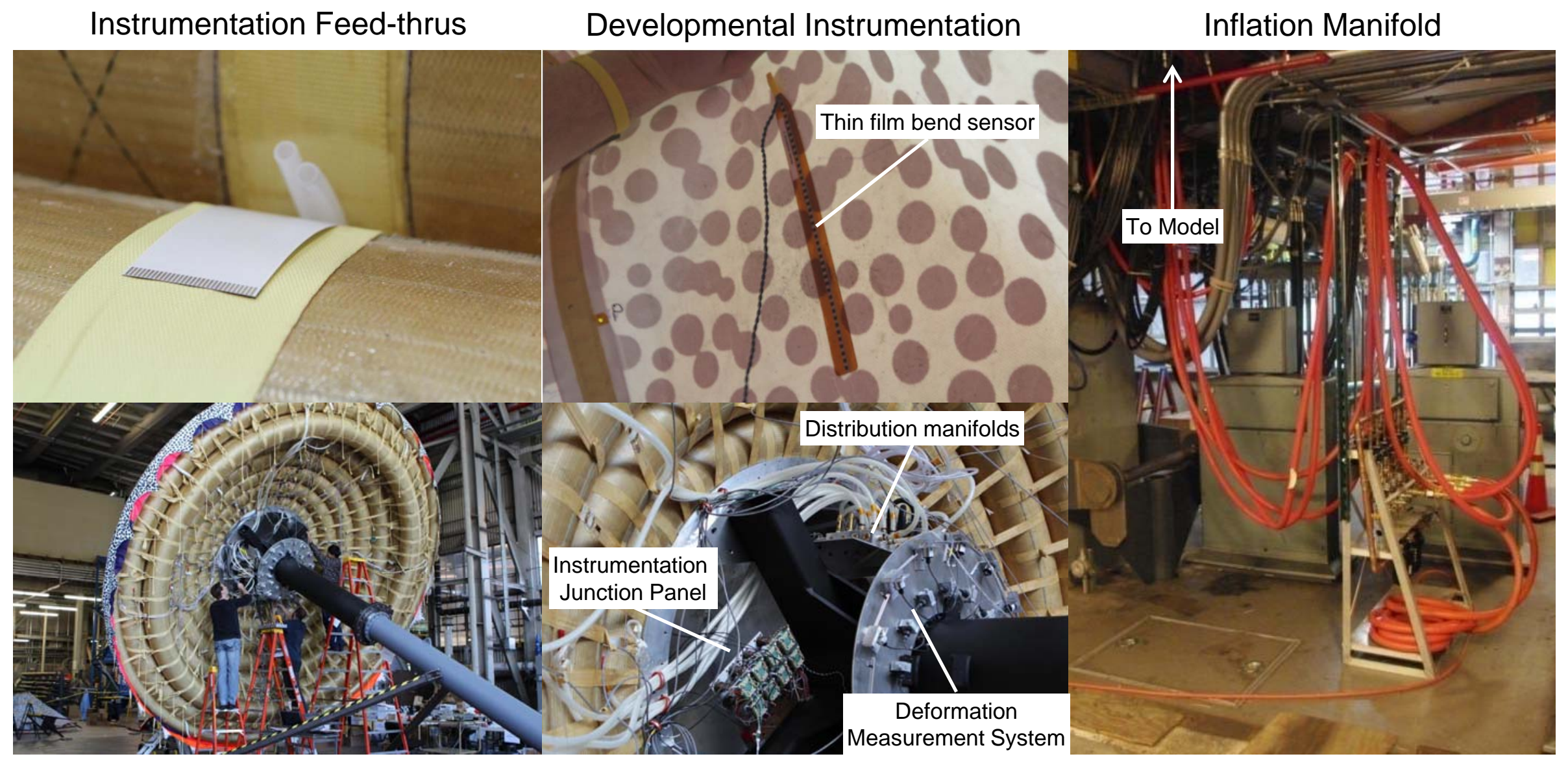

Routing Instrumentation \& pneumatic lines

Sting/Test Article Interface 


\section{Assembly \& Integration}

\section{6 m Aerocover Install}

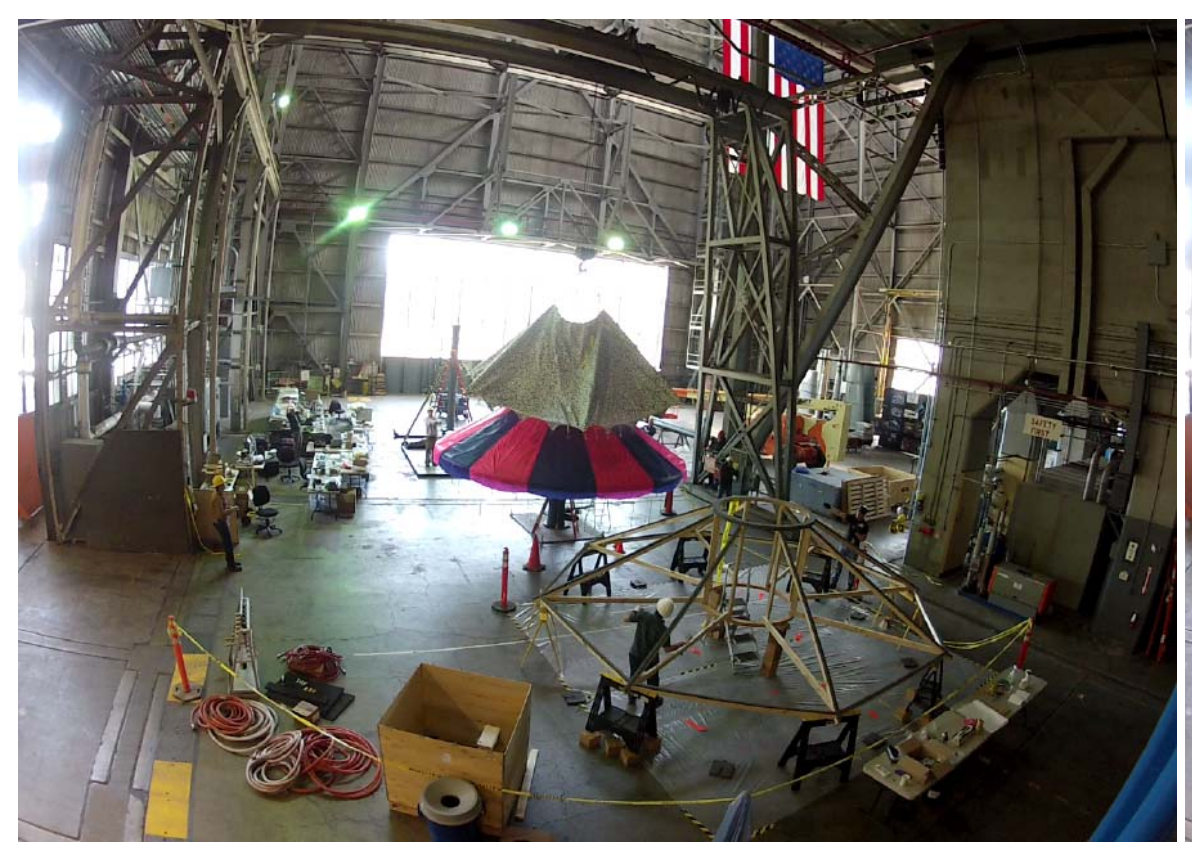

Aerocover Transferred from Integration Fixture to $6 \mathrm{~m}$ HIAD using overhead crane in NFAC high bay

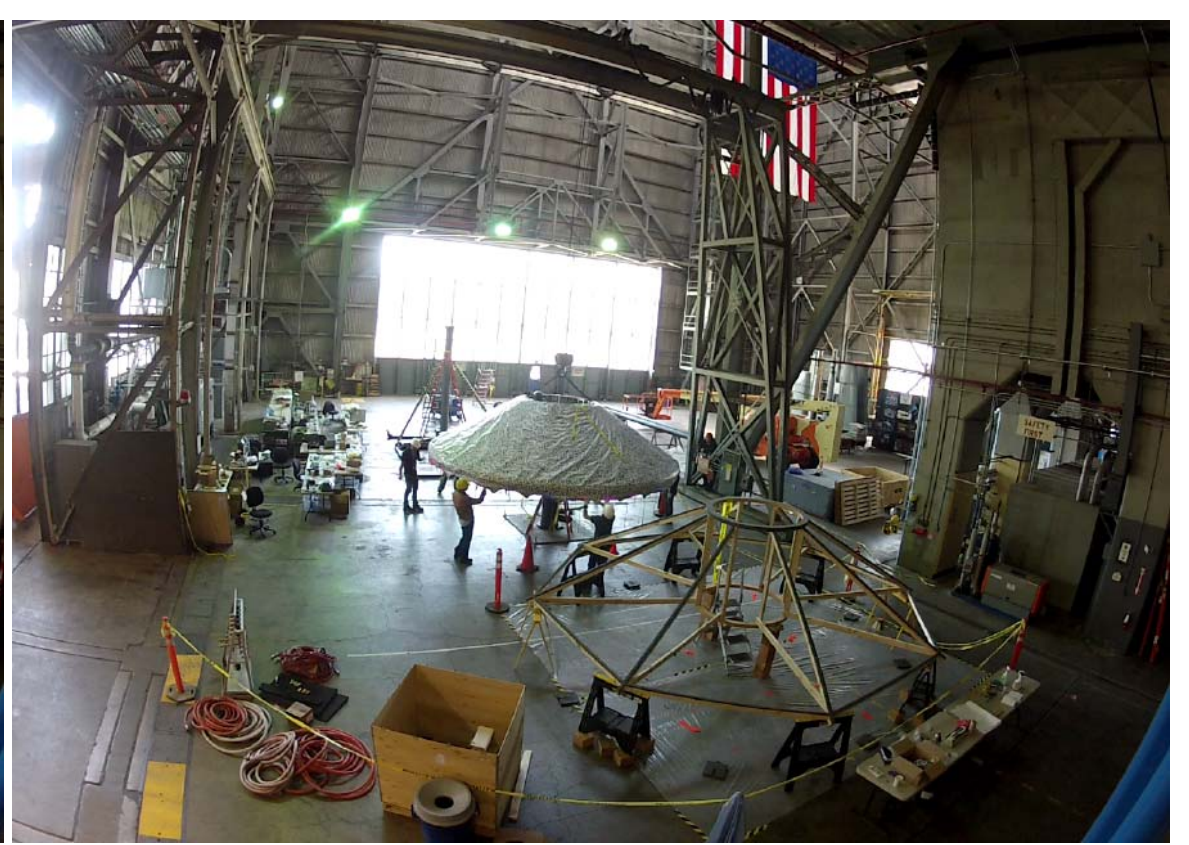

Aerocover Secured to $6 \mathrm{~m}$ Test Article 


\section{Assembly \& Integration}

\section{Custom Support System Hardware}

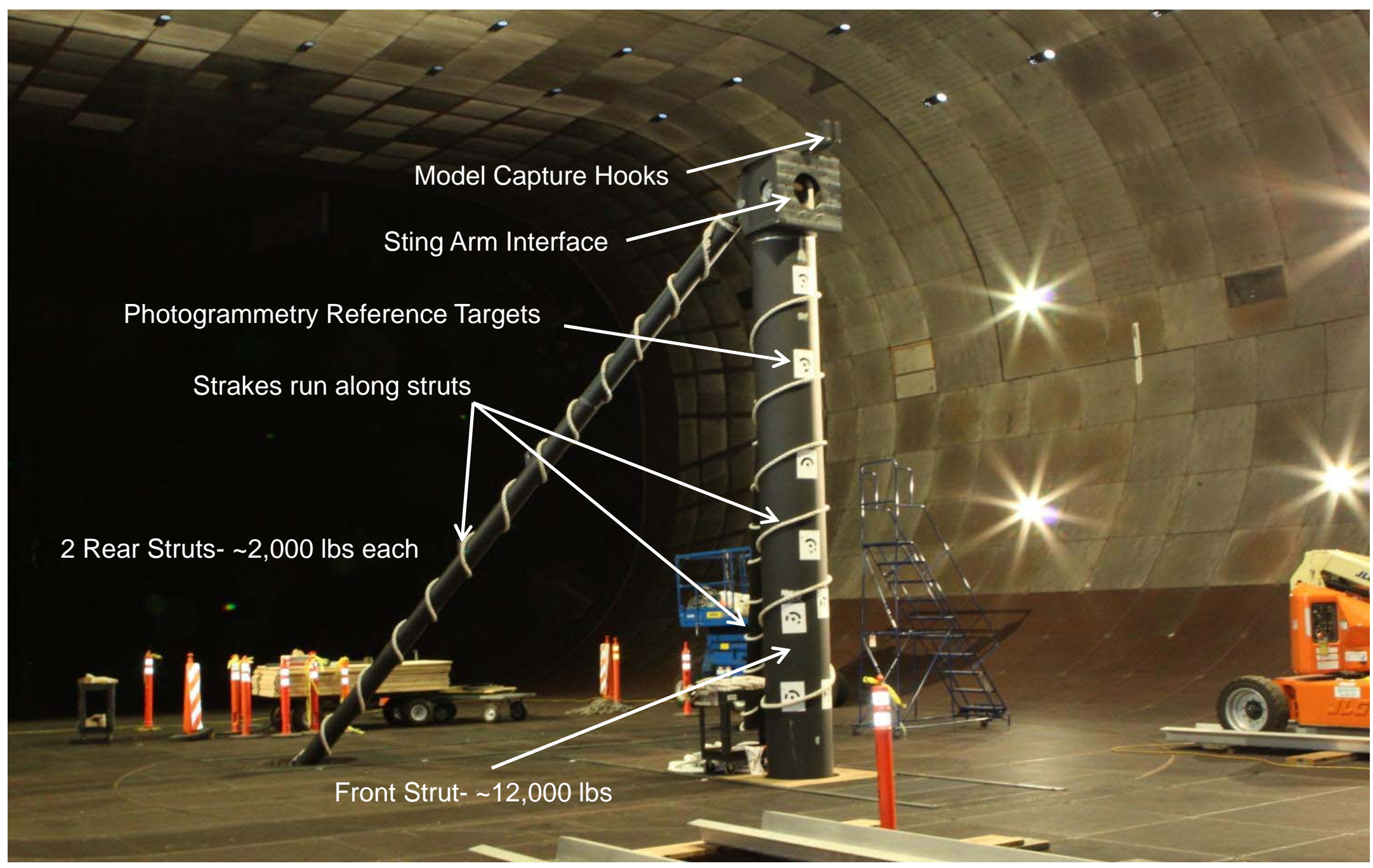




\section{Assembly \& Integration}

\section{Model Installation}

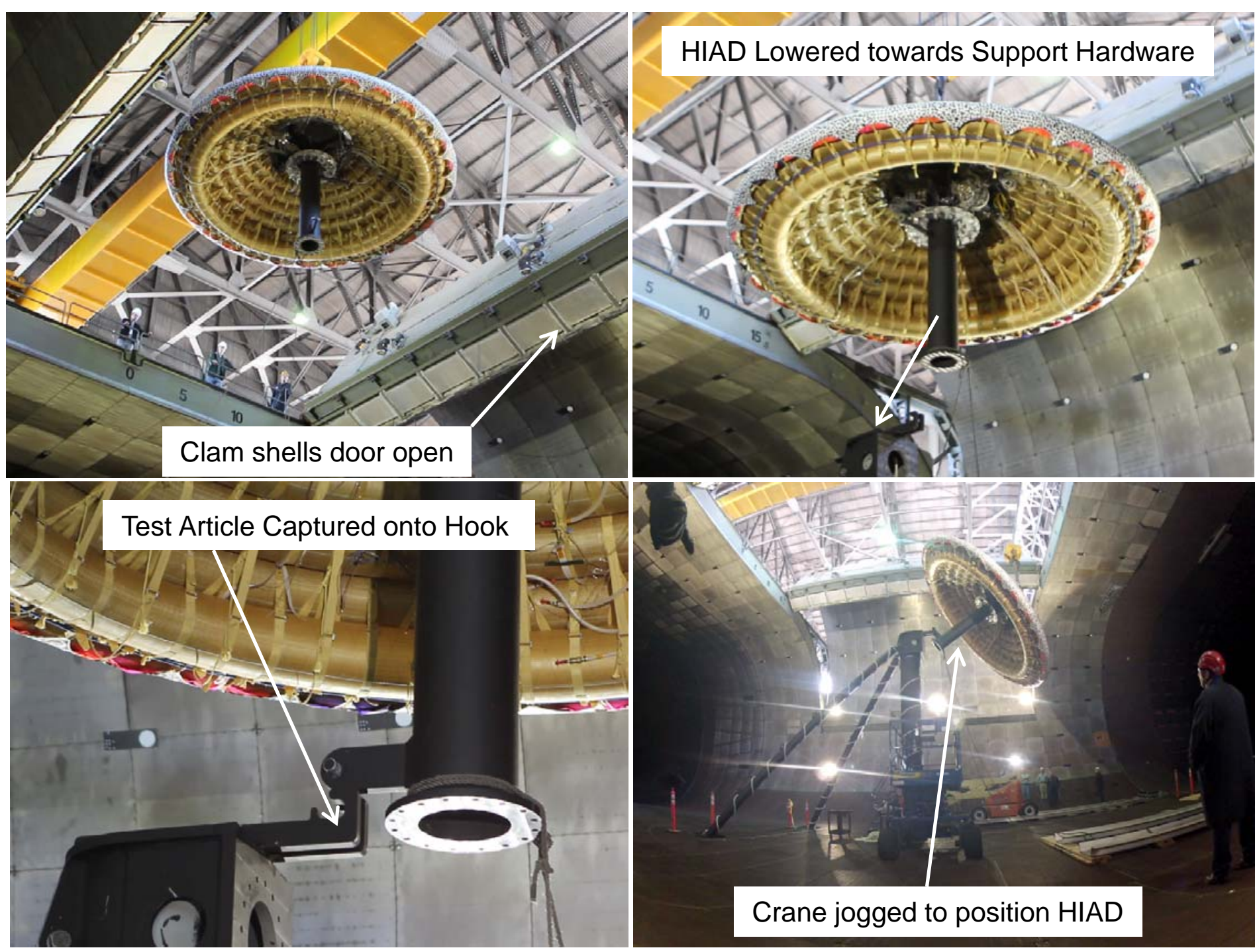




\section{Assembly \& Integration}

Final Assembly in Test Section

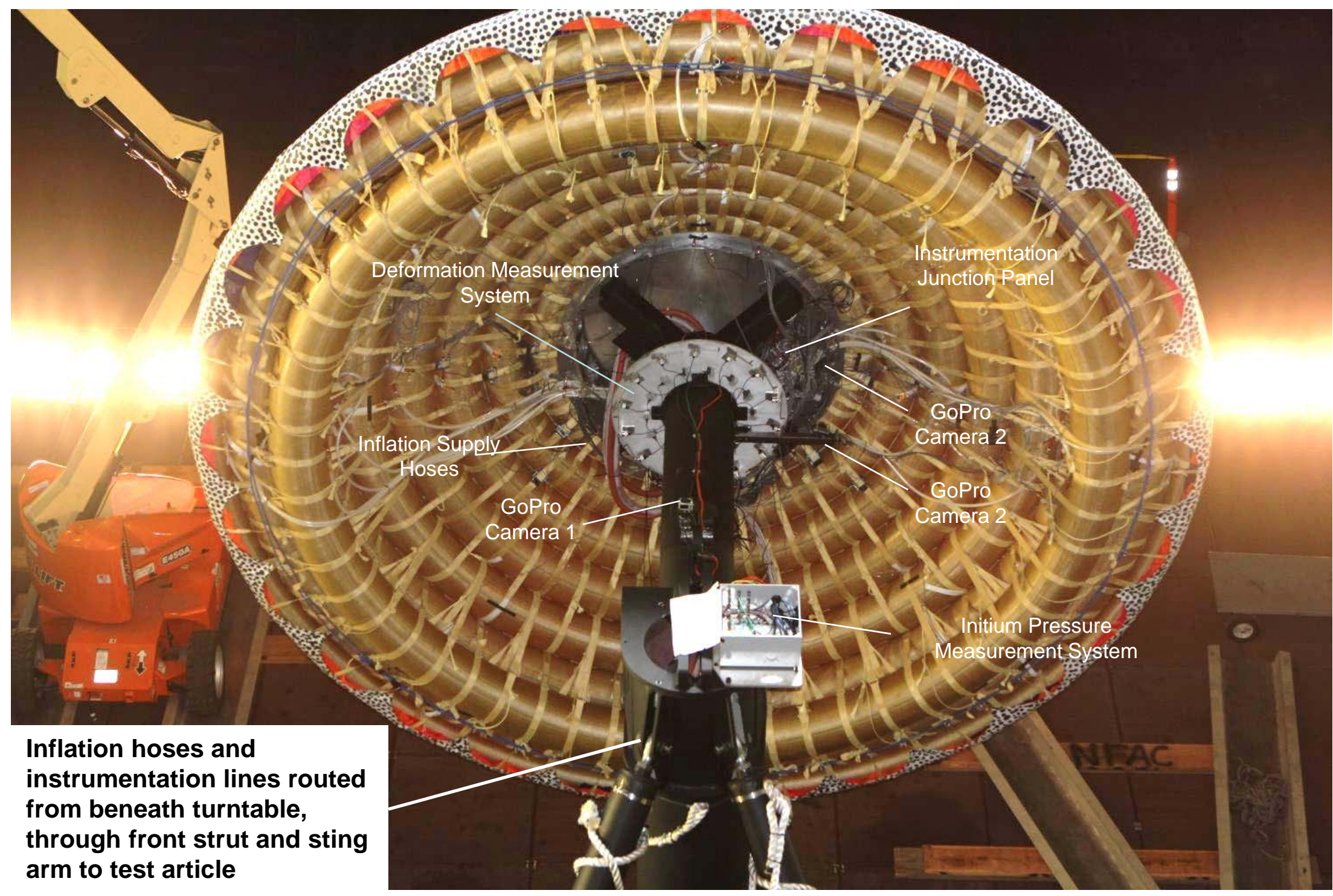




\section{Test Operations}

Test Articles Installed in Wind Tunnel
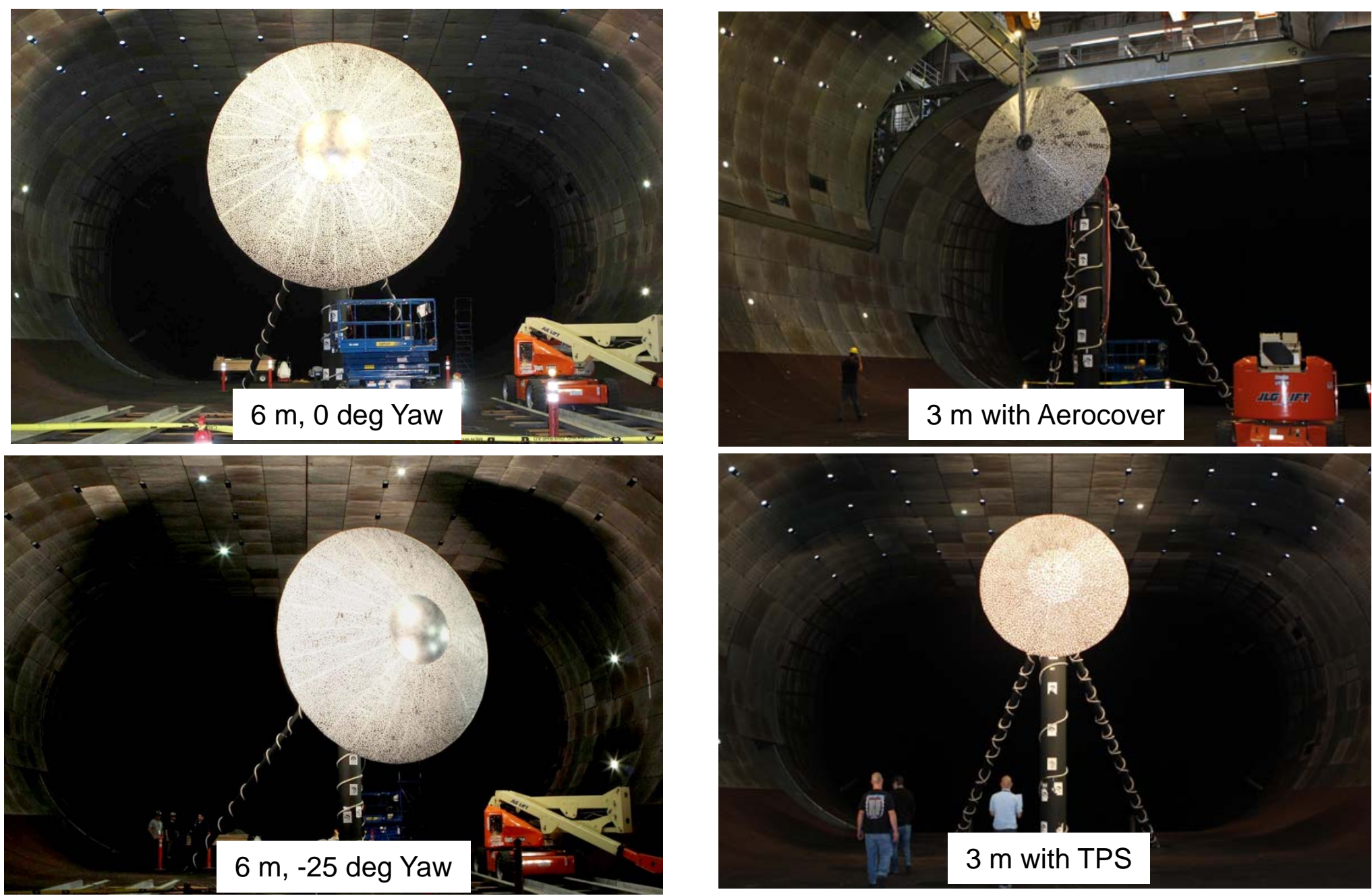


\section{Test Operations}

HIAD Video Compilation 


\section{Photogrammetry System}

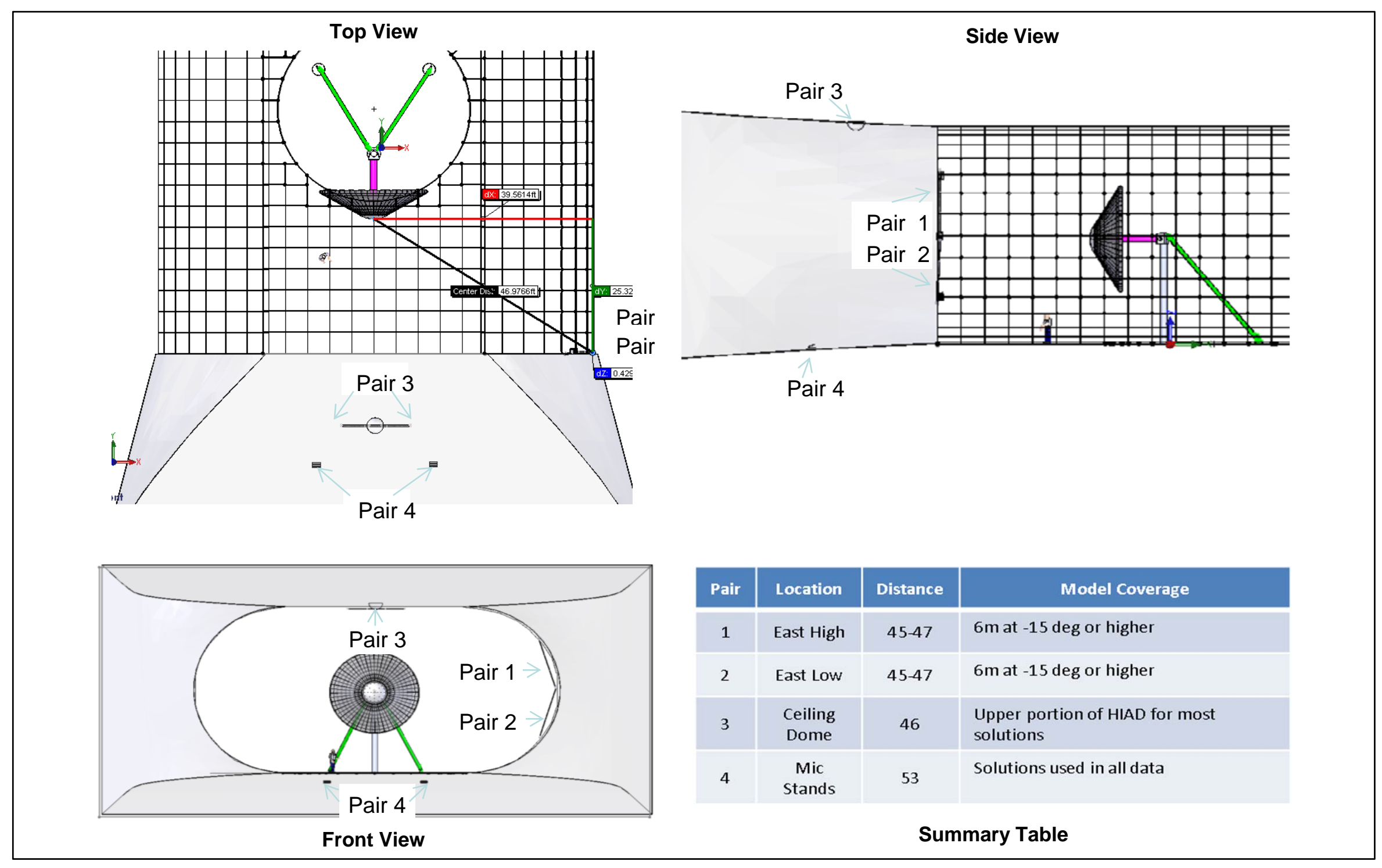




\section{Photogrammetry System}

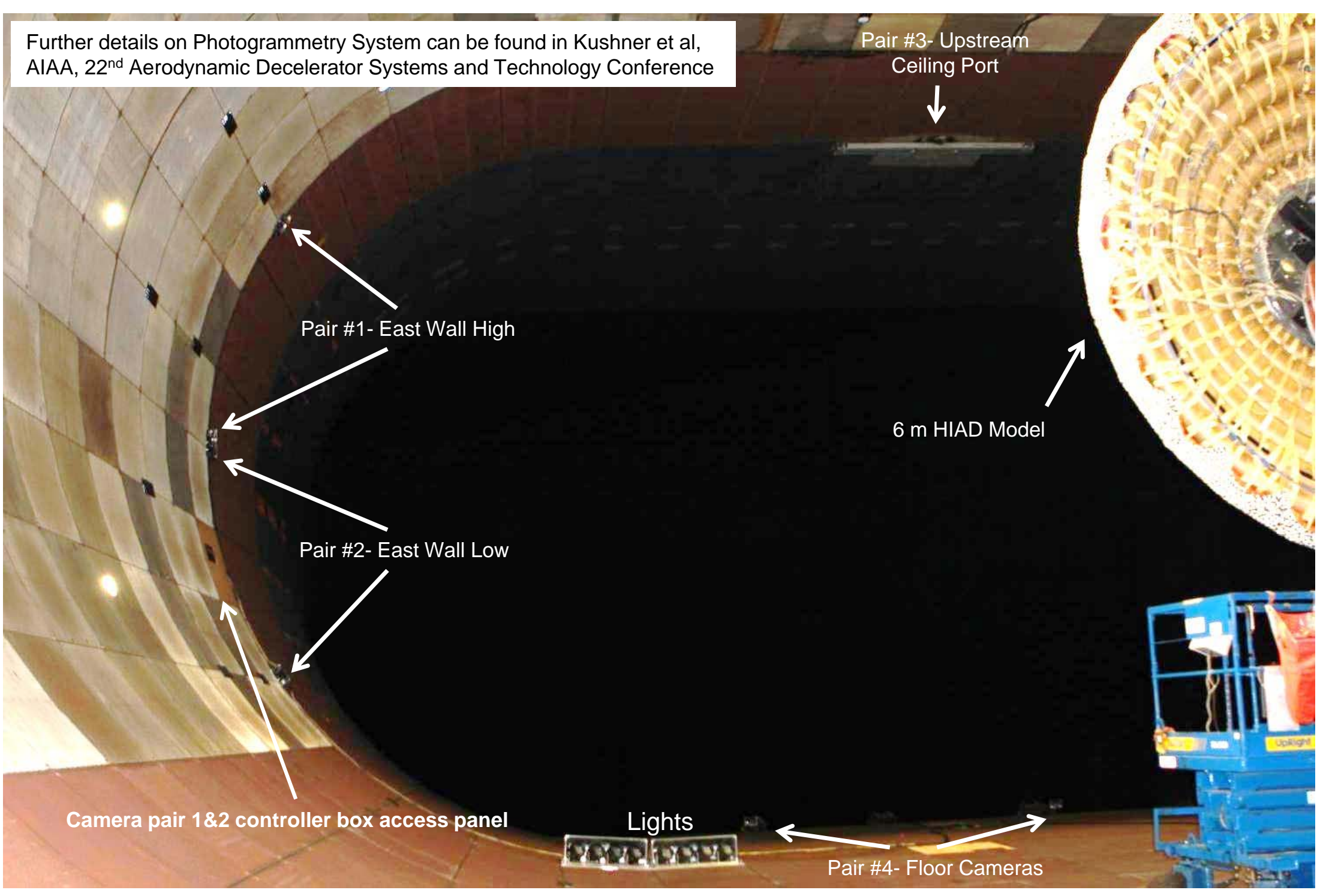




\section{Photogrammetry Data}

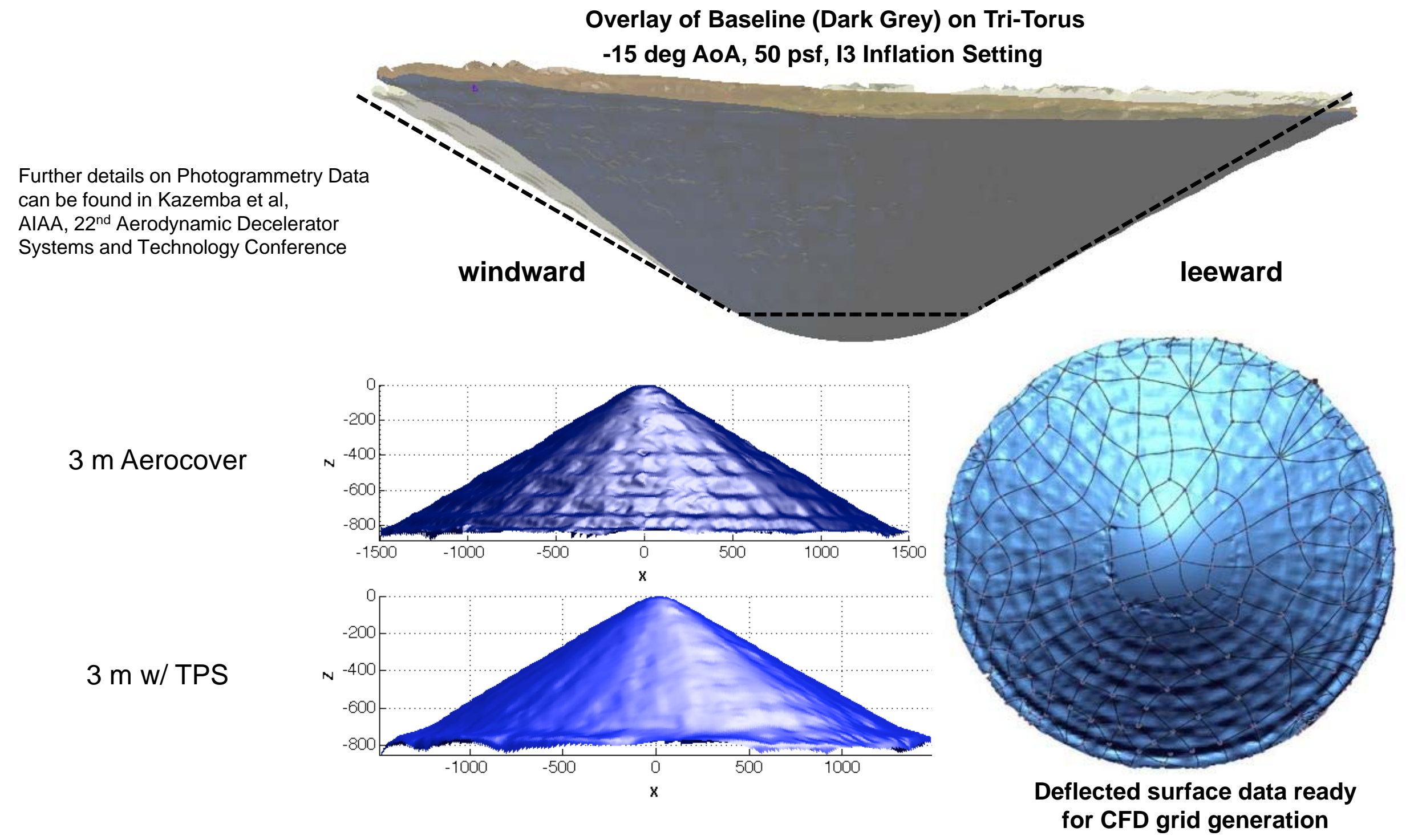




\section{Test Article Surface Pressures}

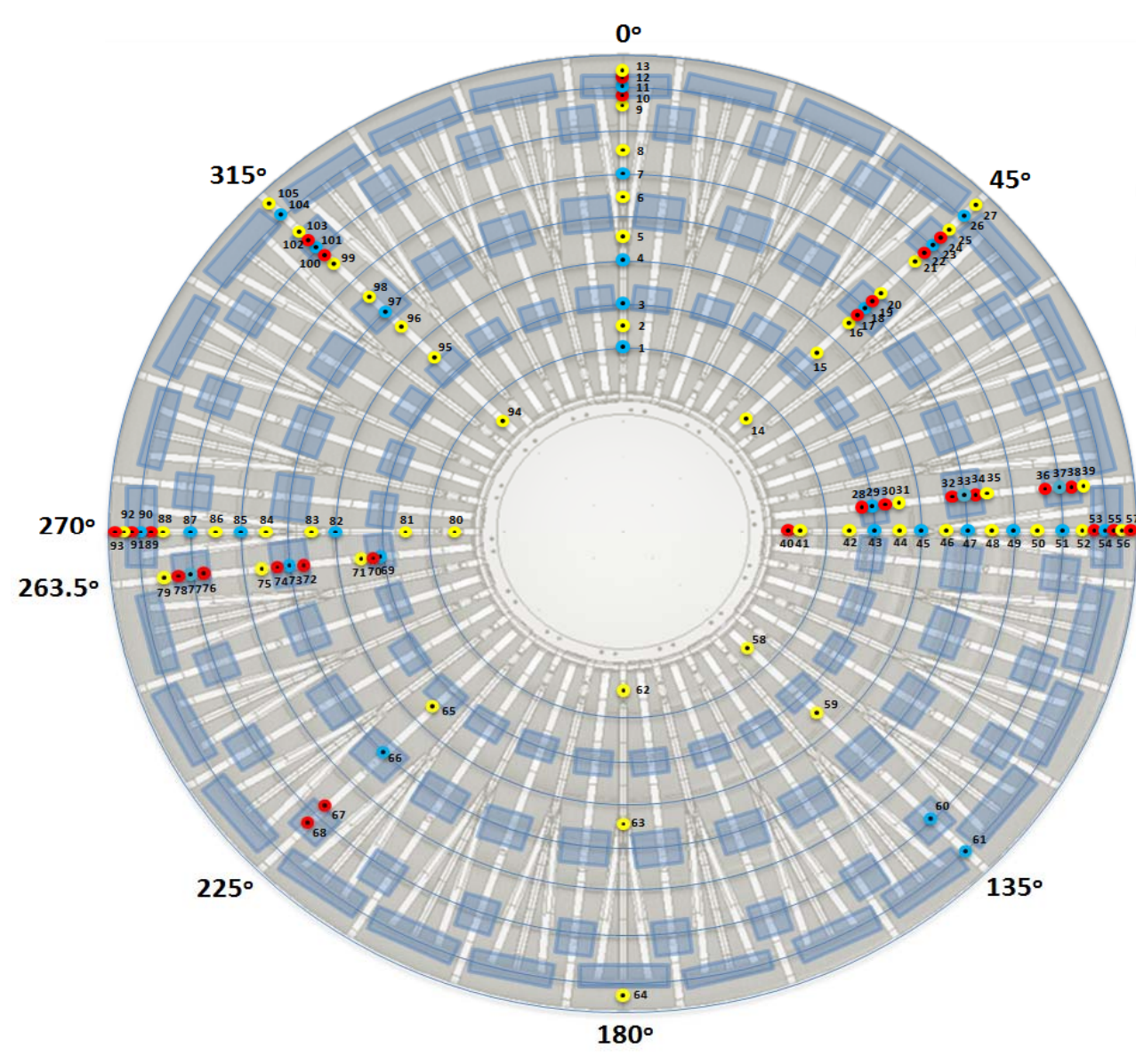

105 Embedded Pressure Taps
Large Unsupported (strap

structure) Aerocover Areas -

Most Likely Largest Areas of Deflection.

- Pressure Tap on Torus Peak

Pressure Tap in Valley
(minimum) of Tori

Pressure Tap Directly Between

Torus Peak and Tori Valley

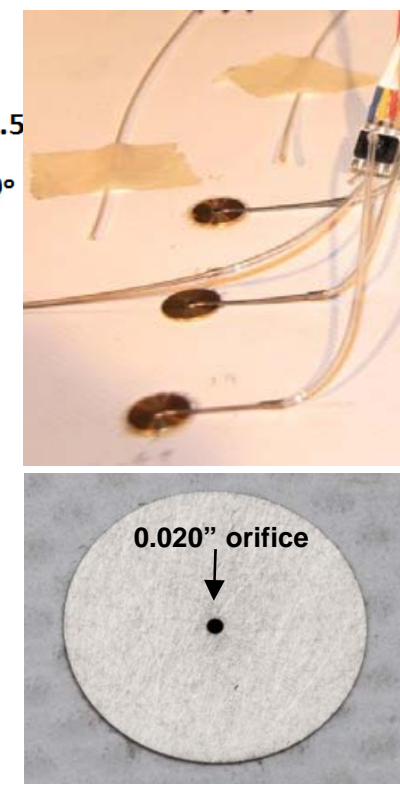

Tap Orifice

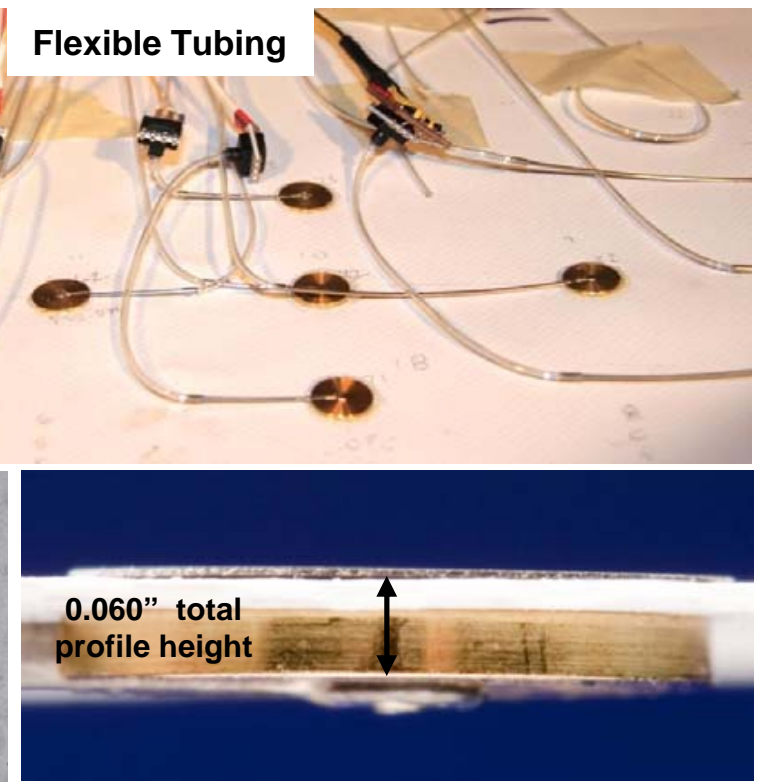

Low Profile Design 


\section{Surface Pressure Data}

Tri-Torus: i2, 50psf, $0^{\circ}$

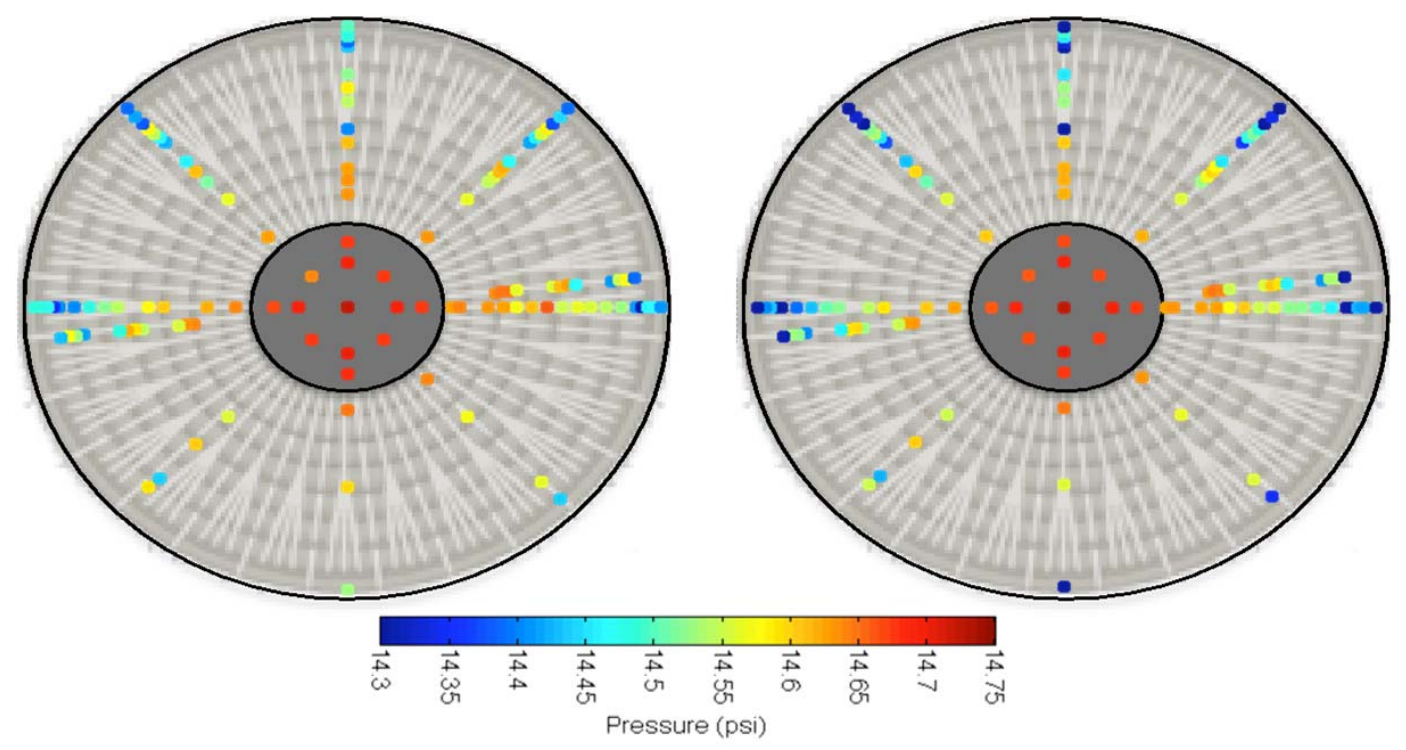

Tri-Torus - Baseline

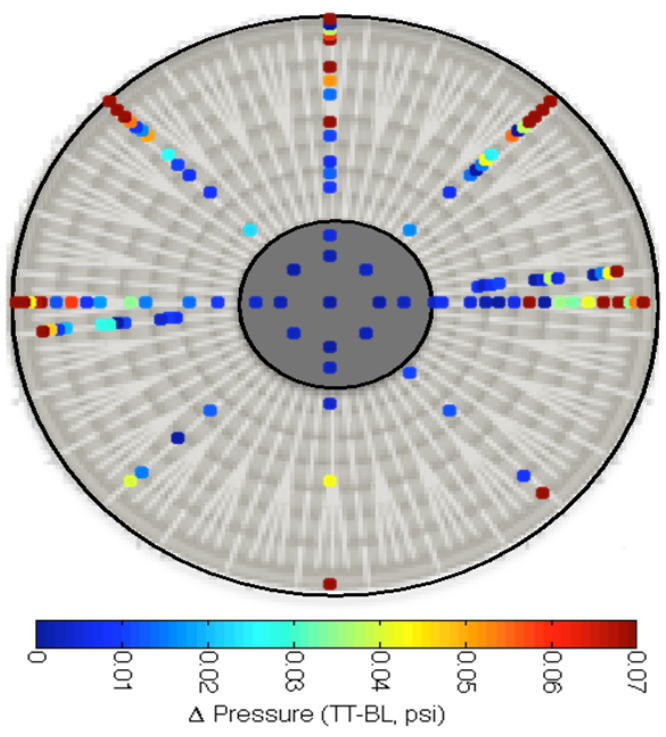




\section{Load Pins \& Load Cells}

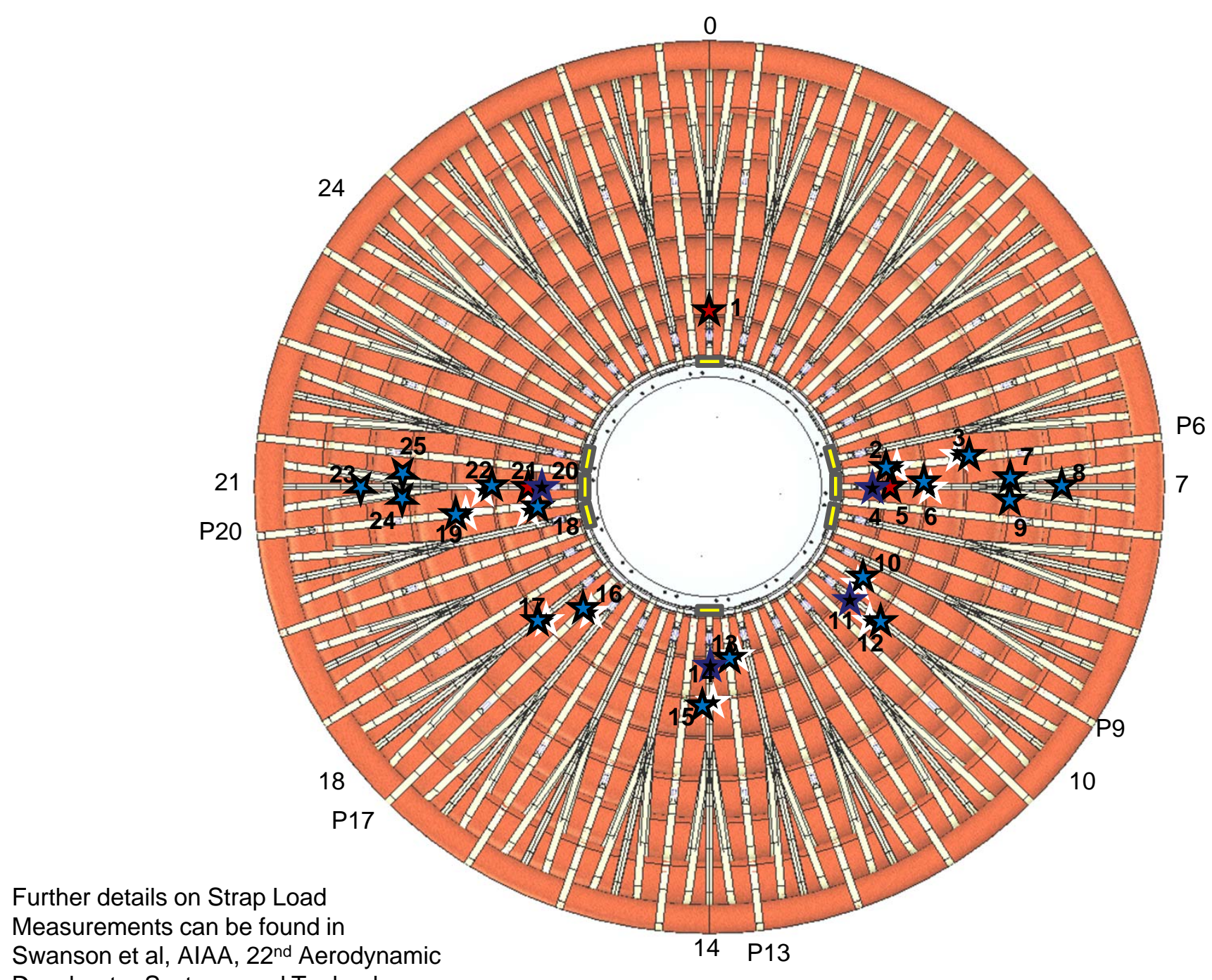

Swanson et al, AIAA, 22 ${ }^{\text {nd }}$ Aerodynamic

Decelerator Systems and Technology

Load Cell Distribution Map

Load Pins- Yellow Bars
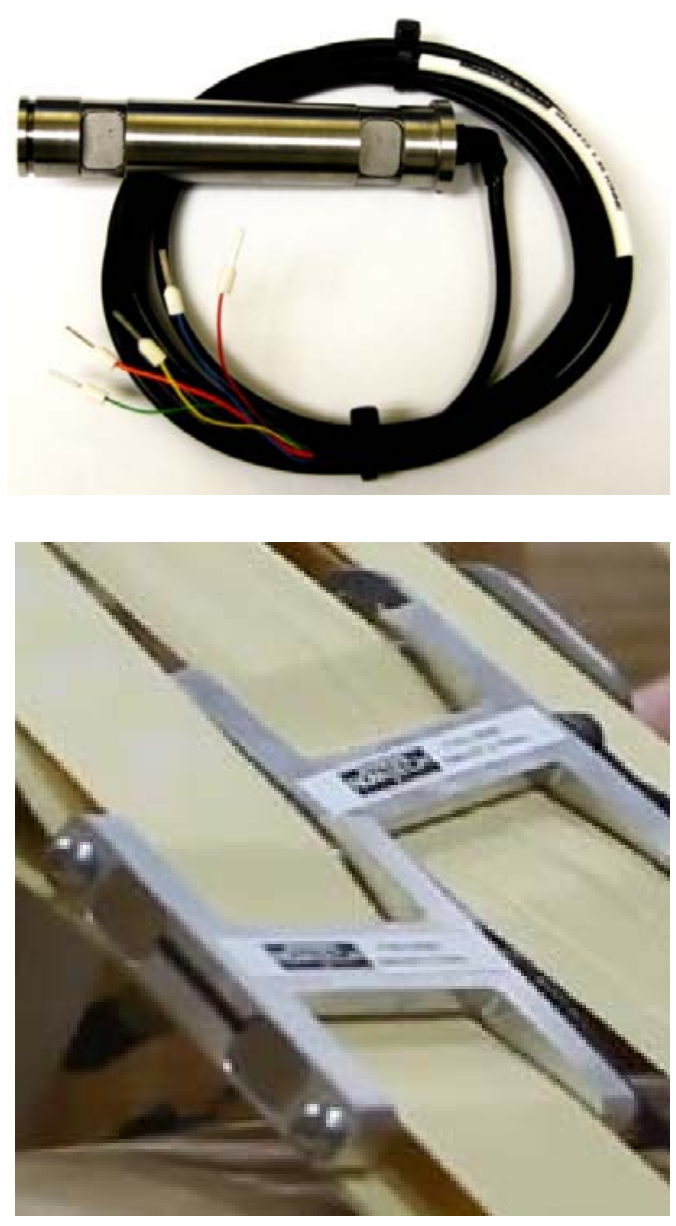

Strap Load Cells- Stars 


\section{Results Overview}

\section{Summary:}

- Very successful test series- all primary test objectives were met

- Two 6 m configurations and two $3 \mathrm{~m}$ configurations tested.

- Comprehensive set of data products- $~ 400$ data channels monitored

- Ability to investigate Aero/Structural performance over a wide range of conditions

- Full 3-d imaging of forward surface for CFD \& FEA model development

- Characterization methodology for structural strap materials

- Embedded instrumentation development for pressure and localized state measurements

\begin{tabular}{|c|c|c|c|c|c|c|c|c|}
\hline \multirow{2}{*}{$\begin{array}{c}\text { Model } \\
\text { Configuratio } \\
\mathbf{n}\end{array}$} & \multirow{2}{*}{$\begin{array}{l}\text { \# Test } \\
\text { Point } \\
\text { s }\end{array}$} & \multicolumn{7}{|c|}{ Primary Data Products } \\
\hline & & $\begin{array}{c}\text { Photogrammet } \\
\text { ry }\end{array}$ & $\begin{array}{l}\text { Strap Load } \\
\text { Cells }\end{array}$ & $\begin{array}{l}\text { Strap Load } \\
\text { Pins }\end{array}$ & $\begin{array}{l}\text { Surface } \\
\text { Pressures }\end{array}$ & $\begin{array}{c}\text { Wall } \\
\text { Pressures }\end{array}$ & $\begin{array}{l}\text { Aero Forces } \\
\text { \& Moments }\end{array}$ & $\begin{array}{l}\text { Inflation } \\
\text { Pressures }\end{array}$ \\
\hline $6 \mathrm{~m}$ Tri-Torus & 151 & $\begin{array}{l}\text { Full Model } \\
\text { Coverage }\end{array}$ & 21 & 8 & 118 & 138 & Yes & Yes \\
\hline $6 \mathrm{~m}$ Baseline & 106 & $\begin{array}{l}\text { Full Model } \\
\text { Coverage }\end{array}$ & 21 & 8 & 118 & 138 & Yes & Yes \\
\hline $3 \mathrm{~m}$ & 94 & $\begin{array}{l}\text { Full Model } \\
\text { Coverage }\end{array}$ & 21 & N/A & 118 & 138 & Yes & Yes \\
\hline $3 \mathrm{~m} \mathrm{wl} \mathrm{TPS}$ & 28 & $\begin{array}{l}\text { Full Model } \\
\text { Coverage }\end{array}$ & 21 & N/A & 5 & 138 & Yes & Yes \\
\hline
\end{tabular}




\section{Acknowledgements- Core Test Team}

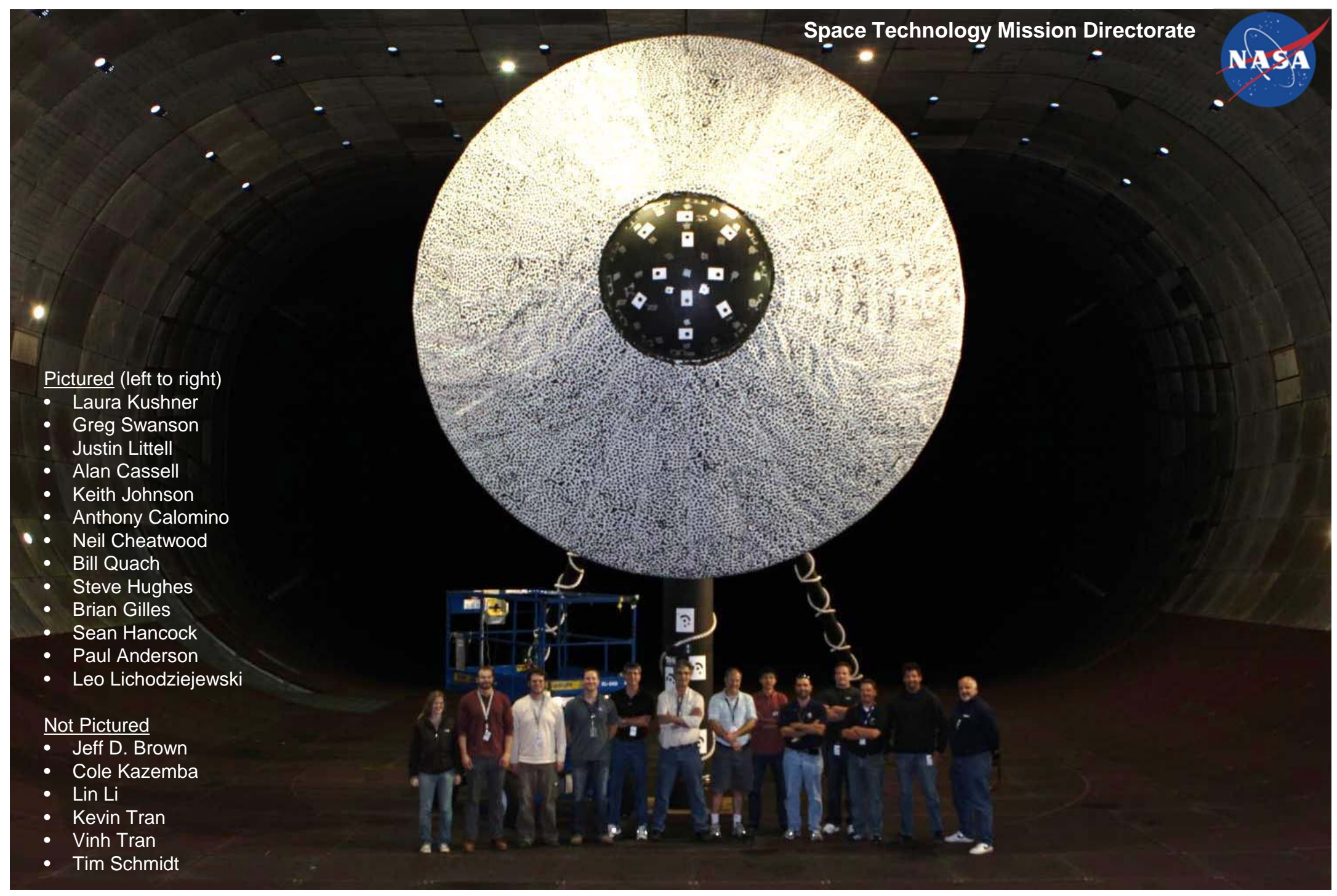




\section{Acknowledgements- Test Team Photo}

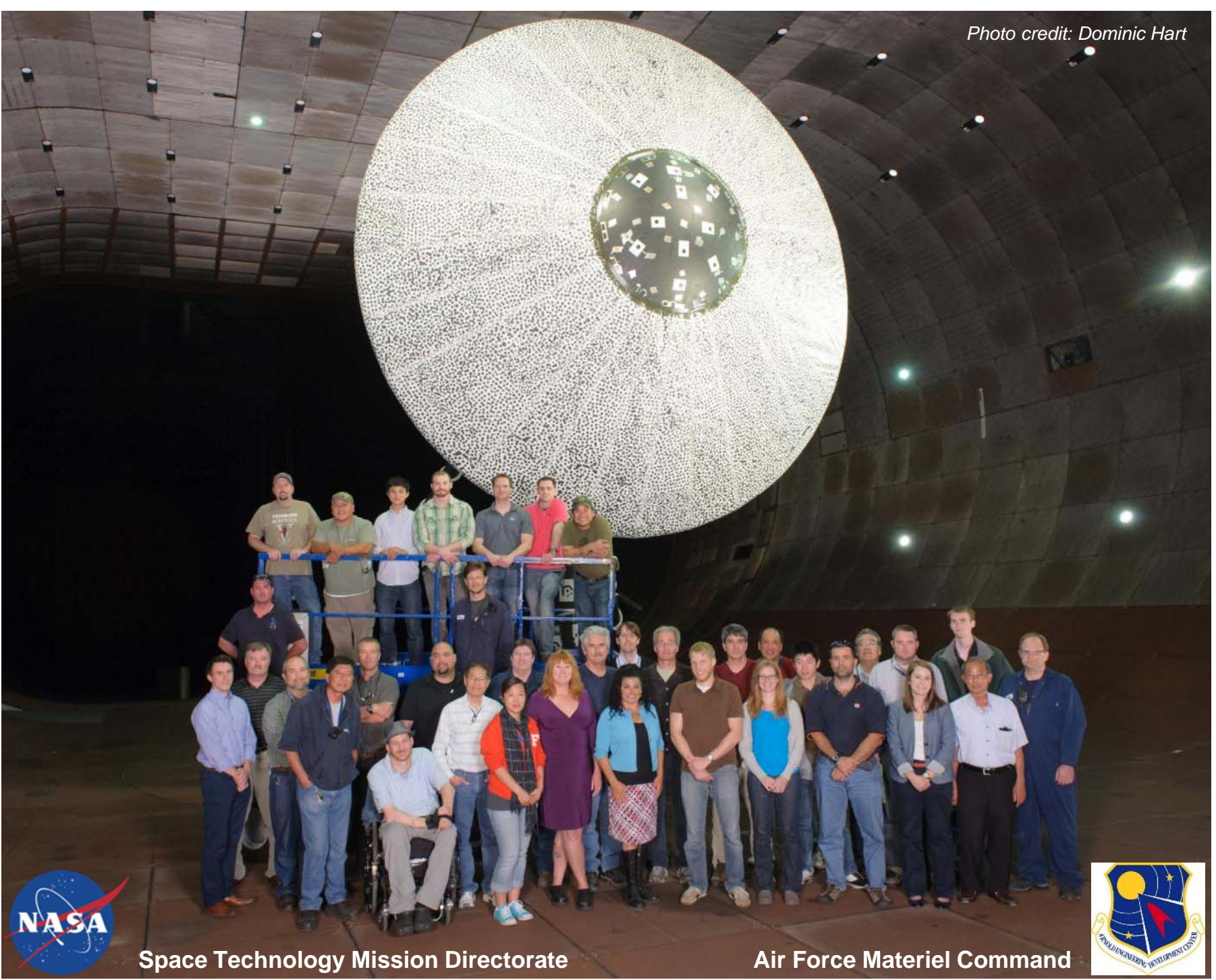




\section{Questions?}

\section{ONINA}

The World's Forum for Aerospace Leadership 